\title{
Salt Gradation Analysis for Winter Road Maintenance
}

\author{
Leila Hashemian $^{a^{*}}$, Neeraj Saroj ${ }^{\mathrm{b}}$, Babak Mehran ${ }^{\mathrm{c}}$, Alireza Bayat ${ }^{\mathrm{d}}$ \\ ${ }^{a}$ Assistant Professor, Department of Civil \& Environmental Engineering, University of Alberta, 7-255 Donadeo Innovation Center of \\ Engineering 9211 116th Street, Edmonton, T6G 1H9, Canada. \\ ${ }^{b}$ Senior Engineer, Roadways and transportation, City of Regina, Sk, Canada. \\ c Assistant Professor, Department of Civil Engineering, University of Manitoba, E1-446 EITC 15 Gillson St. Winnipeg, R3T 5V6, Canada. \\ ${ }^{d}$ Professor, University of Alberta, Department of Civil \& Environmental Engineering, 7-243 Donadeo Innovation Center of Engineering \\ 9211 116th Street, Edmonton, T6G 1H9, Canada.
}

Received 28 May 2020; Accepted 23 July 2020

\begin{abstract}
This research investigates the salt gradation specifications adopted by different provincial or state highway departments in Canada and the US for winter road maintenance operations. To understand the type of used salt, its quantity, grain size distribution, application method and the level of satisfaction of the user, a questionnaire was prepared and sent to selected provincial/state highway departments in Canada and the US. The survey-based comparative analysis performed on the salt gradation in different jurisdictions showed that the salt gradation does not always fit in ASTM (American Society of the International Association for Testing and Materials) and BS (British Standard) standard curves. However, it was found that the gradation of coarse and fine salt used by most Canadian provinces follows ASTM I and the Finnish standards, respectively. Although the majority of jurisdictions surveyed in this study have specific requirements for gradation of the salt used in their winter maintenance operations, no laboratory tests or field trials have been conducted to investigate the effectiveness of a particular salt gradation for road winter maintenance operations. It was also found that salt gradation standards are compromised due to factors such as local availability of the material, purity of the available material, ease of material handling, ease of application, and the preference of private contractors for certain materials.

Keywords: Winter Road Maintenance; Salt Gradation Specification; Coarse Salt Gradation; Fine Salt Gradation; Comparative Study.
\end{abstract}

\section{Introduction}

Winter road maintenance is a critical task of highway maintenance agencies in countries with extreme winter climatic conditions. Solid de-icing road salts are one of the most commonly adopted pavement treatment options by highway maintenance agencies (agencies) during winters [1]. Application of solid de-icing salts, to improve adhesion and smooth flow on ice-covered roadways, is an effective technique for mitigating snow from pavement surfaces, having favorable impact on vehicular floe, public safety, and substantial reduction in travel costs [2]. Different gradations of road salts can be utilized when performing anti-icing or de-icing activities. Most winter maintenance agencies including state or provincial highway departments generally use pre-defined salt gradation specifications that suit their operational requirements. Having pre-defined salt gradation specifications ensures that the de-icing material procurement process is facilitated. This also helps the maintenance agencies adhere to consistent operating and safety standards.

* Corresponding author: hashemia@ualberta.ca

http://dx.doi.org/10.28991/cej-2020-03091573

(c) 2020 by the authors. Licensee C.E.J, Tehran, Iran. This article is an open access article distributed under the terms and conditions of the Creative Commons Attribution (CC-BY) license (http://creativecommons.org/licenses/by/4.0/). 
However, depending on factors like material availability and budgetary constraints (material cost), agencies may sometimes compromise on the salt gradation specifications. Currently, winter maintenance agencies select de-icing salts based on two main factors which are cost of salt product and salt ability to perform under different road climatic conditions. Due to limited available budget for winter maintenance by public road agencies, material cost becomes the most significant factor selection of de-icing product. With that regard, sodium chloride $(\mathrm{NaCl})$ due to its very low cost and high abundance is by the most commonly used salt material for de-icing during snow periods [3, 4]. Although the effectiveness of sodium chloride salt on snow covered roadways depends on various factors, the sodium chloride salt has an excellent performance in terms of de-icing ability at temperatures up to $-9{ }^{\circ} \mathrm{C}$ to $-12{ }^{\circ} \mathrm{C}$. Furthermore recent field investigations have showed that under specific guidelines, sodium chloride salt could be used for de-icing at much lower temperature down to $-20^{\circ} \mathrm{C}$ [5-7].

The highway agencies understand the distinct benefits of both fine and coarse graded materials when used for ice control activities. Also, the percentage purity and particle size of salt material are principally essential considerations in selection and application of salt products for de-icing applications. Precisely, sodium chloride particle size strongly influences the effectiveness and activation time as well as the snow melting time duration on snow covered roadways [8].

Generally, fine salt particles are believed to be more effective anti-icing agents as compared to the coarse salt particles. The higher "specific surface" of the fine salt particles allows easier mixing with snow and ice particles in comparison with coarse particles. However, it has been found that the addition of coarse salt particles to road salt pile may improve the overall performance of salt as an anti-icing agent. There is an increased possibility of the finer salt grains getting blown away easily from the pavement surface due to turbulent air currents created by significantly high volumes and high speeds of traffic movement on the highways in combination with strong wind gusts during winter. Coarse salt grains have larger grain size and are heavier compared to fine salt grains. These properties of the coarse salt allow the particles to remain on the pavement surface for a prolonged period of time. It has been observed that overall wastage of coarse salt is less as compared to fine salt due to lower chances of being blowing away from the pavement surface as well as less slippage through the narrow gaps in the truck bodies used to carry salt [2].

The key objective of utilizing the salt as a de-icing agent is to destabilize the snow or ice bond on the pavement surface. This is done in steps including melting of the snow or ice pack and formation of brine on the pavement surface. Once the bonds are broken, the snow and ice float on the brine solution. The movement of traffic facilitates further breaking the ice chunks and creates a slush that can be mechanically plowed away. Fine salt particles are known to accelerate the snow melting process and formation of brine on the pavement surface. Fine salt particles, therefore, significantly enhance the process of melting and brine formation. However, when applied on thicker snow or ice packs, the finer particles may not penetrate deeper into the snow and may not reach the pavement. Moreover, at lower temperatures refreezing may occur as fine particles may lose their effectiveness by diluting quickly. Theoretically, the addition of coarse particles may enhance the performance of road salt as a de-icing agent as coarse particles will stay on the icy surface for a longer period and allow slower continuous reaction of salt with the ice pack. Ideally a well-blended mixture of coarse and fine salt particles would significantly improve the effectiveness of the road salt both as an anti-icing or de-icing agent. Therefore, suitable salt gradation standards need to be established and practiced by winter maintenance agencies in order to maximize the effectiveness of road salt during de-icing or antiicing activities $[1,9]$.

\section{Objectives and Scope}

This research aims to accomplish the following objectives:

- To review the theoretical and practical aspects of road salt gradation for road winter maintenance operations;

- To investigate the salt gradation standards set by international standardization organizations such as ASTM (American Society of the International Association for Testing and Materials) and BS (British Standard), and national standards in countries such as Finland and Sweden;

- To investigate the salt gradation specifications adopted by different highway departments in Canada and the US and compare them with international standards to provide an overview of the graduation standards adopted by agencies facing similar challenges during winter months.

To understand how highway departments in Canada and the US manage the salt gradation of de-icing materials, an outreach program was planned that included a questionnaire survey, telephonic interview, and in-person meetings and interviews. The collected data were analyzed and compared with available standards for salt particle size distributions set by international organizations. Figure 1 shows the research methodology. 


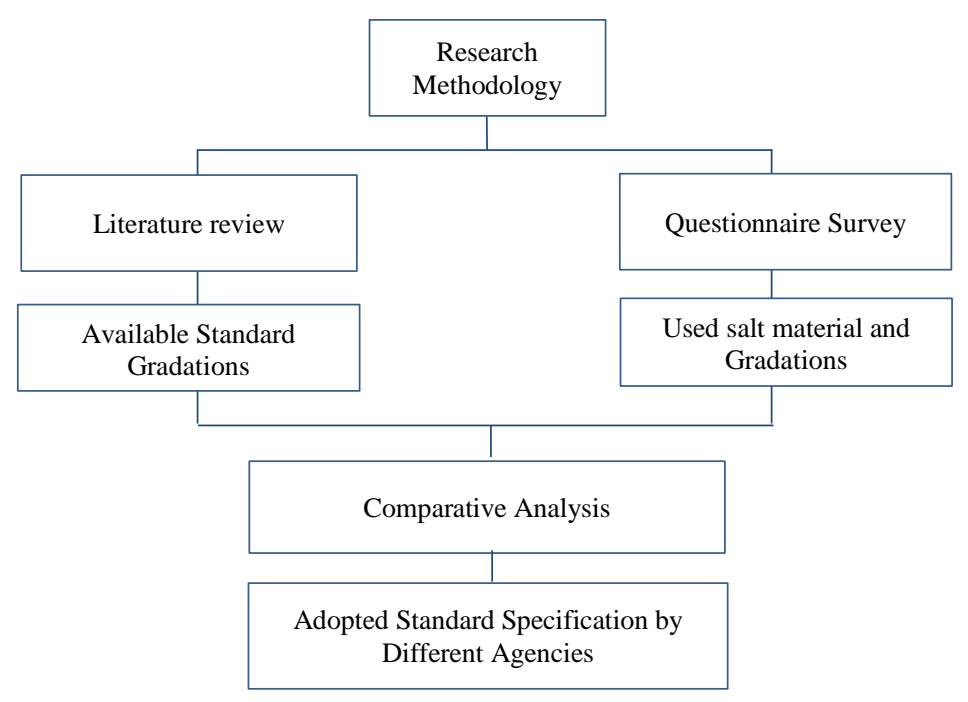

Figure 1. Research Methodology

\section{Background and Previous Studies}

\subsection{Types of Processed Salt Used in Winter Maintenance}

Recently, winter maintenance agencies select de-icing salts based on two main factors which are cost of salt product and salt ability to perform under different road climatic conditions. Sodium chloride $(\mathrm{NaCl})$ due to its very low cost and high abundance is by the most commonly used salt material for de-icing during snow periods [2].

Rock salt or Sodium chloride is the most commonly used ice-control chemical for application on roads and highway in the US and Canada. It is generally produced in three forms namely rock salt, solar salt and evaporated or solution (or vacuum) salt. While the rock salt is mined utilizing conventional hard rock mining equipment and techniques, solar salt is produced by the evaporation of sea water and the evaporated (or solution or vacuum salt) is made by vacuuming and drying the solution created after injecting water into underground salt deposits. Typical characteristics of these processed salts are highlighted in Table 1 [10].

Table 1. Typical characteristics of processed salts

\begin{tabular}{cccc}
\hline Processed salt & Grain size & Moisture content & Impurities \\
\hline Solar salt & Irregular & High to very high & Average \\
Rock salt & $0-5 \mathrm{~mm}$ & Low, $<0.1 \%$ & $1-4 \%$ \\
Vacuum salt & Around $0.6 \mathrm{~mm}$ & Average, around $2.5 \%$ & Low \\
\hline
\end{tabular}

While solar salt is produced in several western states of the USA, some quantity is imported into the eastern US [10]. Canada is a significant consumer of rock salt. It has a vast geographical territory with several known rock salt deposits. In addition, there is a huge potential for new discoveries within Canada. There are only a small number of companies that have currently exploited the vast known reserves in Canada, which are also the major players in Canada's road salt industry including extraction and processing of rock salt. Some of these companies also export rock salt. Canada also imports salt from the USA. Most of the salt is utilized for ice-control applications on roads during winter, production of a vast range of chemicals, and domestic consumption (e.g., table, food-grade, livestock feed) [11].

Major Canadian salt deposits are found in the provinces of Nova Scotia, New Brunswick, Quebec, Ontario, Manitoba, Saskatchewan, and Alberta. The largest rock salt deposits are in western Canada, followed by Ontario and the Atlantic provinces. In western Canada, the rock salt beds start from the Northwest Territories and cover vast regions in Alberta, Saskatchewan, and extend up to Manitoba. Many salt deposits were discovered while these regions were explored for oil, gas and other minerals like potash. This huge salt deposit contains over one million billion tons of salt. The salt deposit is approximately $122 \mathrm{~m}$ in thickness and covers an area of approximately $390,000 \mathrm{~km} 2$ [11].

Review of the 2009 data indicates that in Canada,: $93.0 \%$ of the salt was mined as rock salt from major rock salt mines located in Ontario, Quebec, and New Brunswick, 6.0\% of the production was using fine vacuum method from vacuum pan salt refineries in Alberta, Saskatchewan, Ontario, New Brunswick, and Nova Scotia, and 1.0\% was produced as brine or salt recovered as part of chemical operations. The majority of the salt production was rock salt that was used for highway de-icing activity [11]. 


\subsection{Application Types and Significance of Gradation}

Solid ice-control road salts are the most effective anti-icing agents when applied before ice forms on the pavement. Other case studies show that solid chemicals (e.g., salt) could be effectively used when applied at traffic speeds under about $50 \mathrm{~km} / \mathrm{h}$ and traffic volumes under 100 vehicles per hour as a pre-treatment [12]. Some studies indicate that using salt with "coarser" gradation or particle size distribution is very appropriate for de-icing operations [13]. The reason is that large salt particles melt through the surface and cause ice melt as well. This will continue until the existing bond between pavement surface and ice is broken and at this stage it would be possible to remove the snow or ice mechanically. However, fine graded salt may be frozen or washed out of the pavement surface, hence; using fine graded salt for de-icing operations is generally not cost effective compared to the use of coarse graded salt [12].

\subsubsection{Fine Grained Salt}

Fine graded salt has a high dilution potential and may blow off the road surface because of moving traffic and winds. Hence, it is not suitable for de-icing operations [12].

Comparing to coarse grain salt, fine salt dilutes much faster and as a result, it should be reapplied more frequently and with a greater volume to have the same effectiveness as coarse salt at the same weather conditions. The reason is that it melts quickly and produces a wet pavement surface. However, this situation will not last for a long time since the wet surface will re-freeze again if the temperature is extremely low. The best application of fine graded salt is for the treatment of thin ice layers on the road surface and also for pre-treatment just before the daylight when pre-wetted [13].

As a preventive operation for black ice formation during the fall and spring when the pavement temperature is around $0^{\circ}$ to $-3^{\circ} \mathrm{C}$, fine grained salt may be applied as solution or liquid salt. In this case liquid salt should be applied up to three hours before any precipitation happens or road surface becomes frozen. The advantages of using liquid salt are: decreasing the total amount of used salt, its instant melting effect, and not splashing against car windshields [12].

In situations where the pavement temperatures are lower than $-5^{\circ} \mathrm{C}$ or application on compacted ice is considered, liquid salt is not recommended. In addition, although application of liquid salt is not recommended in freezing rain conditions, occasionally it has been used with increased application rate up to 40 to $60 \mathrm{~g} / \mathrm{m} 2$. For roads with low traffic volume (less than 2,000 ADT) the effectiveness of liquid salt is lower [12].

The major disadvantages of using liquid salt is increasing the operators workload since after application; they need to observe the road surface continuously to make sure it is not frozen. Also, the salt brine is very corrosive and may damage the spreading equipment and its electrical connections quicker compared with coarse grain salt [12].

\subsubsection{Coarse Grained Salt}

The success of salt spreading has a strong relationship with its grain size distribution. If the salt grain is fine, it makes the ice melt fast on the surface; however, the resulting brine refreezes rapidly and will not penetrate to the surface adequately. On the other hand, large salt grains $(3$ to $5 \mathrm{~mm}$ ) slowly penetrate into the pavement surface, stay longer on the road but need more time to work since they dissolve at a slower rate. Another problem with coarse grain salt is that large grains may bounce back to the road shoulder during the spreading operations [12].

The commonly used salt for anti-icing or de-icing operations is sodium chloride. A mix of solid sodium chloride and solid calcium chloride or calcium chloride solely has also been used by some agencies. The grain size distribution of the salt that is used for anti-icing treatment is very similar to what is designed for de-icing operations, without prewetting conditions [10].

Based on the research conducted in various European countries, the ideal salt grain size used in winter maintenance ranges from 0.16 to $3 \mathrm{~mm}$, with a low percentage (maximum 5\%) ranging below $0.16 \mathrm{~mm}$ or between 3 and $5 \mathrm{~mm}$ and not greater than $5 \mathrm{~mm}$. However, some countries have regulation to use large grain salts (at least $5 \%$ ) because of its deep-acting effect [12].

In Canada, a study conducted by researchers at the University of Waterloo [14] concluded that salt gradation has great impact on the performance of the de-icing salt. A comparative study was conducted between coarse road salt with average particle size of almost $6.5 \mathrm{~mm}$ (the majority of the material being in the range of 4 to $9 \mathrm{~mm}$ ); and fine road salt with average particle size of $4.3 \mathrm{~mm}$ (the majority of the material within the range of 1.6 to $7 \mathrm{~mm}$ ); and another road salt (referred to as UW salt) with average particle size of $2.5 \mathrm{~mm}$ (the majority of the material $<5 \mathrm{~mm}$ ). The performance comparison of different salt gradations was conducted by creating a salting rate model to calculate the appropriate salting rate considering various conditions such as temperature, salt weight concentration, and the time taken for the pavement to become $80 \%$ or more snow and ice free (bare pavement regain time). The results showed that the fine graded road salt was $20 \%$ more effective than coarse road salt, and the UW road salt was approximately $60 \%$ more effective than coarse road salt as the coarse salt can be easily dispersed by vehicular traffic. It is worth 
mentioning that this study was conducted on parking lots, so the results may not be similar on highways due to the impact of moving traffic.

Another study at the University of Nebraska [15] investigated the impact of salt gradation on refreeze time. It was shown that there is a strong relationship between salt grain size distribution and its refreeze time. Samples with gradations smaller than $0.422 \mathrm{~mm}$ (sieve \#40) were refreezing very fast, while samples with larger grain size salts of about $2.38 \mathrm{~mm}$ (\#8 sieve) were refreezing after two hours.

Table 2 summarizes the advantages and disadvantages of using different gradations of salt for de-icing and antiicing applications.

Table 2. Typical characteristics of processed salts

\begin{tabular}{|c|c|c|c|}
\hline Agent & Application & Advantages & Disadvantages \\
\hline \multirow[t]{2}{*}{ Coarse Salt } & De-icing & $\begin{array}{l}\text { - Provides increased traction } \\
\text { - Can penetrate the snow lifts quicker due to its } \\
\text { weight in comparison to fine salt } \\
\text { - Can be mixed with sand } \\
\text { - Needs longer time to leach to the nearby soils } \\
\text { as it takes time to dissolve compared to fine } \\
\text { and liquid salt } \\
\text { - Can be used either dry or pre-wetted }\end{array}$ & $\begin{array}{l}\text { - Can be rolled and displaced towards the road shoulders due to } \\
\text { traffic movement } \\
\text { - May not be effective below certain freezing points (depending } \\
\text { on salt type; }-6^{\circ} \text { to }-25^{\circ} \mathrm{C} \text { approx.) } \\
\text { - It has a dilution potential } \\
\text { - Takes time to dissolve, melt and start working as it comes in } \\
\text { relatively larger grains compare to fine salt } \\
\text { - Overuse of salt can impact the surrounding environment and } \\
\text { infrastructure }\end{array}$ \\
\hline & Anti-icing & $\begin{array}{l}\text { - Pre-wetted salt can remain on the paved } \\
\text { surface. } \\
\text { - A suitable gradation is appropriate in the } \\
\text { absence of pre-wetting. }\end{array}$ & $\begin{array}{l}\text { - Not appropriate because of long dilution time } \\
\text { - Cannot stay on the paved surface due to wind and traffic } \\
\text { - Needs minimum moisture to trigger the effectiveness of the dry } \\
\text { chemical }\end{array}$ \\
\hline \multirow[t]{2}{*}{ Fine Salt } & De-icing & $\begin{array}{l}\text { - Needs short time to melt and start working } \\
\text { - Can easily be mixed with liquids } \\
\text { - Can be mixed with sand } \\
\text { - Can be used either dry or pre-wetted } \\
\text { - Needs longer time to leach to the nearby soils } \\
\text { compared to liquid salt }\end{array}$ & $\begin{array}{l}\text { - Can be blown away during spreading } \\
\text { - May not be effective below certain freezing points (depending } \\
\text { on salt type; }-6^{\circ} \text { to }-25^{\circ} \mathrm{C} \text { ) } \\
\text { - It has a dilution potential } \\
\text { - It takes time to dissolve and penetrate snow/ice lifts } \\
\text { - Overuse of salt can impact the surrounding environment and } \\
\text { infrastructure }\end{array}$ \\
\hline & Anti-icing & $\begin{array}{l}\text { - Its use will decrease the time for a solution } \\
\text { compared to coarse salt }\end{array}$ & $\begin{array}{l}\text { - Due to their larger surface area, they need to be heavily wet with } \\
\text { a liquid to stand up to traffic and wind fairly well. } \\
\text { - Spreading truck speed should not be so high }\end{array}$ \\
\hline \multirow[b]{2}{*}{$\begin{array}{l}\text { Liquid } \\
\text { Salt/brines/other } \\
\text { liquid chemicals }\end{array}$} & De-icing & $\begin{array}{l}\text { - May be used in limited situations for de-icing } \\
\text { if the treatment is immediately followed by } \\
\text { an application of solid chemicals. }\end{array}$ & $\begin{array}{l}\text { - Since liquid ice control chemicals are mostly water, they are } \\
\text { already fairly well diluted. They are not well suited to de-icing } \\
\text { operations as they have little ability to penetrate thick snow ice. }\end{array}$ \\
\hline & Anti-icing & $\begin{array}{l}\text { Can work immediately after spraying } \\
\text { - Easy to handle/control and spray } \\
\text { - It is most effective when used for black ice and } \\
\text { during preventive operations } \\
\text { - Higher friction and better pavement conditions } \\
\text { early in a storm }\end{array}$ & $\begin{array}{l}\text { - Cannot be mixed with sand as it will be difficult to spry } \\
\text { - Ineffectiveness at pavement temperatures below }-5^{\circ} \mathrm{C} \\
\text { - Not recommended during either a freezing rain or sleet storm } \\
\text { because of the large quantity needed to retain an effective } \\
\text { concentration } \\
\text { - Overuse can impact the surrounding environment and } \\
\text { infrastructure } \\
\text { - Needs less time to leach down to nearby soils compared to } \\
\text { coarse and fine salt. }\end{array}$ \\
\hline
\end{tabular}

\subsection{International Salt Gradation Standards}

The American Society of the International Association for Testing and Materials (ASTM) Specifications of natural sodium chloride from rock salt deposits or manmade produced salt by evaporation, solar or other methods are covered by ASTM D632-12 [16]. This standard recognizes two types and grades as below:

- Type I: used primarily as a pavement de-icer or in aggregate stabilization;

- Type II: used in aggregate stabilization or for purposes other than de-icing.

The grading of Type I sodium chloride shall conform to the following requirements for particle size distribution: 
- Grade 1: According to ASTM D632-12 [16], this grading is suitable for general applications and under most conditions is effective for increasing skid resistance and ice control

- Grade 2: this grading is typically being used and preferred for salt produced in the western US and states of the Rocky Mountains. The specifications are shown in Table 3.

Table 3. ASTM D632 (2012), Type I, specification for salt gradation

\begin{tabular}{lccccccc}
\hline Sieve size & $(\mathbf{m m})$ & $\mathbf{1 9 . 0}$ & $\mathbf{1 2 . 5}$ & $\mathbf{9 . 5}$ & $\mathbf{4 . 7 5}$ & $\mathbf{2 . 3 6}$ & $\mathbf{6 0 0}$ \\
\cline { 2 - 7 } & & $3 / 4$ in & $1 / 2$ in. & $3 / 8$ in. & No. 4 & No. 8 & No. 30 \\
\hline Grade I (Mass \% passing) & 100 & 100 & $95-100$ & $20-90$ & $10-60$ & $0-15$ \\
Grade II (Mass \% passing) & 100 & ---- & ---- & $20-100$ & $10-60$ & $0-15$ \\
\hline
\end{tabular}

\subsubsection{British Standard (BS)}

The British Salt Standard [17] has specifications for two different grades i.e. rock salt and vacuum salt. According to the British road authority, compliance with the gradation will enhance the spreading ability of the coarse salt for treating snow and ice [12]. BS salt gradation standard requirements are shown in Table 4.

Table 4. BS salt gradation requirements as a percentage passing [17]

(a) Gradation I

\begin{tabular}{ccccc}
\hline Sieve size & $\mathbf{1 0 ~} \mathbf{~ m m}$ & $\mathbf{6 . 3} \mathbf{~ m m}$ & $\mathbf{2 . 3 6} \mathbf{~ m m}$ & $\mathbf{3 0 0} \boldsymbol{\mu m}$ \\
\hline Rock Salt & \multicolumn{4}{c}{ Mass \% passing } \\
Coarse (BS I) & 100 & 75 to 95 & 30 to 70 & 0 to 20 \\
Fine (BS II) & 100 & 100 & 30 to 80 & 0 to 20 \\
\hline
\end{tabular}

(b) Gradation II

\begin{tabular}{ccccc}
\hline Sieve size & $\mathbf{1 0 ~} \mathbf{~ m m}$ & $\mathbf{6 . 3} \mathbf{~ m m}$ & $\mathbf{1 . 1 8} \mathbf{~ m m}$ & $\mathbf{1 5 0} \mathbf{\mu m}$ \\
\hline Vacuum Salt & & \multicolumn{3}{c}{ Mass \% passing } \\
Coarse (BS III) & 100 & 100 & 0 to 80 & 0 to 10 \\
Fine (BS IV) & 100 & 100 & 100 & 0 to 30 \\
\hline
\end{tabular}

\subsubsection{Finnish Standard}

In 1989, studies were conducted on the effect of rock salt gradation and the Finnish National Road Administration revised the specifications after that [9]. The outcome of the study showed that a finer gradation had better result with pre-wetting operations. In the original standard it was required that $100 \%$ of the material should pass through a 6 -mm sieve, while the revised standard changed the 6-mm sieve to 5-mm. Table 5 shows the requirements for Finnish standard.

Table 5. Finnish salt gradation specifications [10]

\begin{tabular}{ccccccc}
\hline Sieve size $(\mathbf{m m})$ & $\mathbf{5}$ & $\mathbf{4}$ & $\mathbf{3}$ & $\mathbf{2}$ & $\mathbf{1}$ & $\mathbf{0 . 5}$ \\
\hline Mass \% passing & 100 & $90-100$ & $70-100$ & $40-90$ & $15-55$ & $3-25$ \\
\hline
\end{tabular}

\subsubsection{Swedish Standard}

Based on the studies conducted by the Swedish Transport Administration, the salt's origin does not have significant influence on its melting effect [10]. However, the grain size distribution is very important.

Fine-grained salt can prevent formation of thin ice layers on the pavements surface while coarse salt is more effective in slush producing during the snowfall. The Swedish gradation specifications are shown in Table 6 . Figure 2 compares all mentioned standard gradations.

Table 6. Swedish gradation specifications [10]

\begin{tabular}{ccccc}
\hline Sieve size $(\mathbf{m m})$ & $\mathbf{3}$ & $\mathbf{2}$ & $\mathbf{0 . 5}$ & $\mathbf{0 . 1 6}$ \\
\hline Mass $\%$ passing & $95-100$ & $65-100$ & $26-50$ & $5-26$ \\
\hline
\end{tabular}




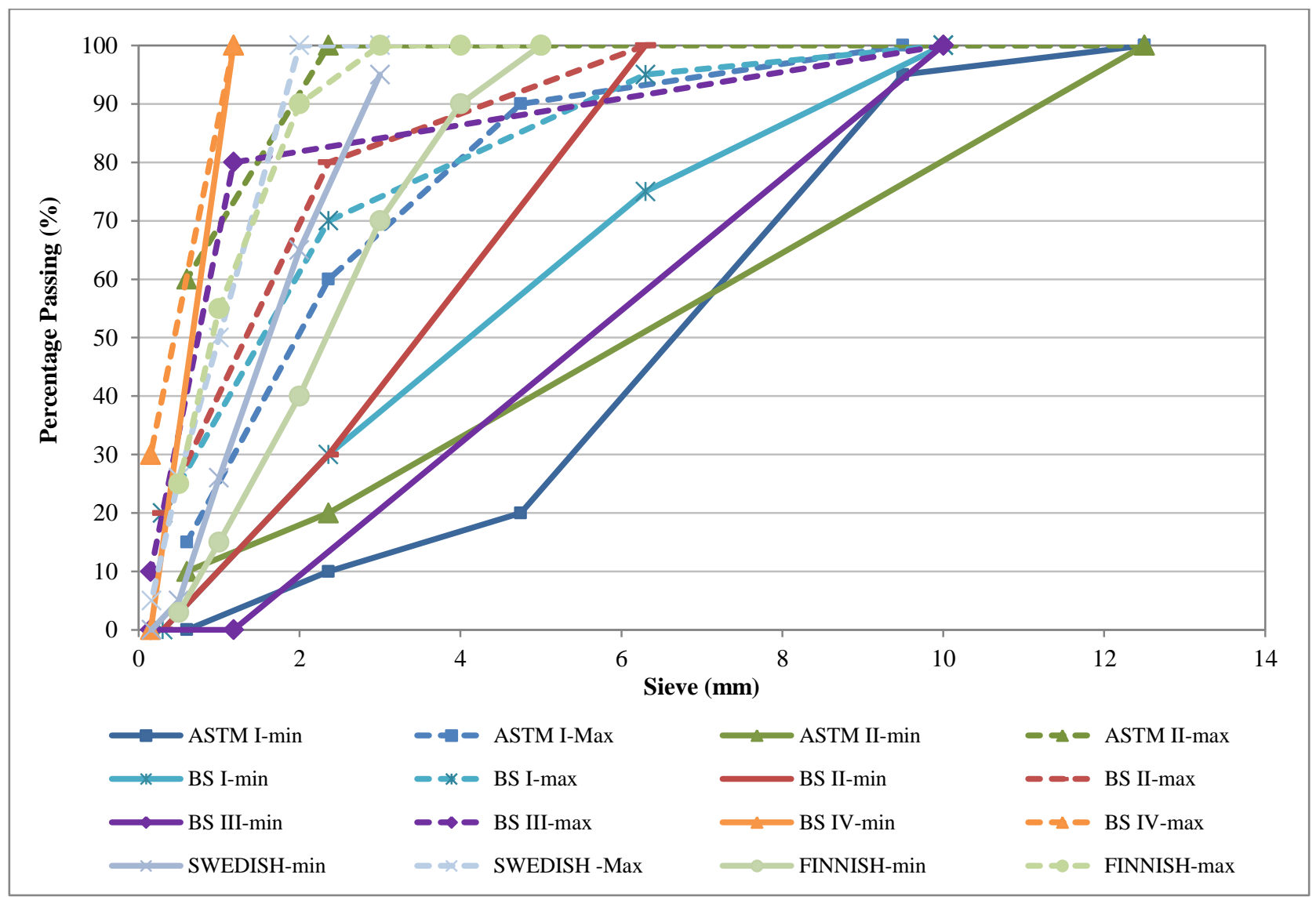

Figure 2. Comparison of available standard salt gradations

\section{Data Collection and Results}

\subsection{Questionnaire Survey}

A questionnaire-based survey was sent to selected provincial/state highway departments in Canada and the US. The questionnaire included the following questions:

1. What salt gradation does your organization use for de-icing operations in winter?

2. What is the flexibility of using salts with different gradations, i.e., do you always adhere to the above gradation for salt? If no, then under what situations a different gradation of salt would be used? Is there other gradation of salt used in the above situations?

3. Please rate your organization's level of satisfaction with the current salt gradation on a scale of 1 to 5 . In your opinion, what are the advantages and disadvantages of the current salt gradation used by your organization?

4. Has your organization ever conducted trials on salt gradation? If yes, please provide a brief description of the trials and findings.

5. How much salt do you consume in an average winter season (quantity in tons)?

\subsection{Telephonic Interviews}

Telephonic interviews were conducted with concerned officials from most of the above organizations to explain the purpose of the research and to provide any clarifications about the questionnaire.

\subsection{Field Level Feedback (Anecdotal)}

As part of the research, some field professionals from the winter maintenance industry were contacted including heavy duty truck mechanics from the highway departments, experienced contractor truck operators, and field representatives of the companies directly involved in calibrating the electronic controllers for de-icing trucks operated by highway departments or their contractors. The feedback received from these sources was used to crosscheck the survey findings. 


\subsection{Data Collection Results}

Out of six responses received from the Canadian provinces (Nova Scotia Department of Transportation and Infrastructure; Government of Alberta, Ministry of Transportation; British Columbia Ministry of Transportation; Ministère des Transports du Québec; Ministry of Transportation of Ontario; Manitoba Infrastructure) and four responses from the Department of Transportation organizations in the US (Departments of Transportation (DOT) of North Dakota, District of Bismarck; Washington State; Michigan; New York State) it was found that most of these jurisdictions have well-defined salt gradation standards in place. However, a majority of them do not completely adhere to their gradation specifications at all times. The salt gradation standards are compromised due to factors such as local availability of the material, purity of the available material, ease of material handling, ease of application, and the preference of private contractors for certain materials. Some organizations chose a gradation specification that was suitable both for direct pavement application as well as in the form of a solution. Often the gradation specifications serve as high level guidelines for the operating and procurement departments as well as material suppliers. Organizations with multiple gradation specifications, like DOT New York State and the Ministry of Transportation of Ontario, tend to adhere closely to one of the specifications.

The study found that respondents generally considered coarse grade material more suitable for direct application on the pavement as it prevented the formation of a bond between the ice and pavement by staying longer on the pavement surface. The general handling of the coarse-graded material was considered convenient and safer. However, some organizations chose a finer grade material because of the ease of mixing in a solution without leaving any residue, as well as the ability to utilize it as a direct application product on the pavement. The organizations using fine grade material did mention the high amounts of material wastage due to leakage during transportation, particularly during direct application.

For Alberta, the major deciding factor was the local availability of the material. The British Columbia Ministry of Transportation does not have a preferred salt gradation and depend on their experienced contractors to choose the deicing material.

Organizations like Nova Scotia Department of Transportation and Infrastructure and DOT North Dakota, District Bismarck prefer fine grade material as they also use the material to make brine solution in addition to using it for road salt application. The fine grade material produces less sediment in the brine solution and dissolves quickly compared to the coarse material. However, both organizations have received complaints regarding wastage due to the fine grade material leaking from the ice control truck bodies when applying straight salt on the roads.

The Ministère des Transports du Québec is quite satisfied with the coarser material as it stays on the ground for a longer period of time and it is easier to handle and apply.

Organizations like DOT Washington State, DOT New York State and the Ministry of Transportation of Ontario use different material gradation specifications based on the application. Fine grade material is used when applying the material in the form of a solution and coarse grade material is used when applying directly on the pavement.

\subsection{Comparative Analysis of Salt gradations}

Tables $7 \mathrm{a}$ to $7 \mathrm{j}$ reflect salt gradations used by different provinces in Canada and the US obtained from the survey results, and Table 8 shows the comparison of these gradations with available standards. For example, Figure 3 shows a comparison between ASTM I and II gradations with Alberta and Saskatchewan coarse salt gradations. Based on the analysis, results are summarized in Table 8 and the following conclusions are drawn:

- Saskatchewan's coarse salt gradation is best fitted with ASTM II, while its mixed gradation fits in BS III gradation. The medium and fine gradations cannot be fitted into any standard curve; however, the medium gradation is close to the Finnish standard gradation;

- Alberta's coarse salt gradation meets ASTM I and II and also BS III gradations. Fine gradation is almost similar to BS IV while medium gradation cannot be fitted into any standard gradations;

- Nova Scotia's salt gradation is within ASTM I gradations;

- North Dakota's salt gradation meets BS III and Finnish gradations;

- Quebec's salt gradation also meets ASTM I specifications;

- Manitoba's minimum limit of salt gradation meets both ASTM I and II standards, while the maximum limit is finer than the defined range in these two standards; the maximum limit is closer to ASTM II;

- New York State's minimum limit of all salt gradations (Types A, B, C) match with the BS II standard while their maximum limits match with ASTM II. Overall, the gradations are close to ASTM II; 
- Michigan DOT's salt meets both ASTM I and II gradation standards;

- Washington State's salt "Category A" gradation matches with ASTM II while the category B maximum limit is slightly finer than ASTM II; however, the difference seems not to be significant.

Table 7. Salt gradation of different jurisdictions

a. Saskatchewan's salt gradation

\begin{tabular}{ccccccccc}
\hline & \multicolumn{7}{c}{ Mass percentage passing (\%) } \\
\cline { 2 - 9 } Sieve size (mm) & \multicolumn{2}{c}{ Coarse } & \multicolumn{2}{c}{ Mixed } & \multicolumn{2}{c}{ Medium } & \multicolumn{2}{c}{ Fine } \\
\cline { 2 - 9 } & min & max & min & max & min & max & min & max \\
\hline 12 & 100 & 100 & 100 & 100 & 100 & 100 & 100 & 100 \\
9 & 70 & 100 & 100 & 100 & 100 & 100 & 100 & 100 \\
5 & 45 & 100 & 65 & 100 & 100 & 100 & 100 & 100 \\
2 & 10 & 55 & 35 & 85 & 60 & 100 & 85 & 100 \\
0.9 & 0 & 15 & 15 & 60 & 35 & 85 & 40 & 100 \\
0.4 & 0 & 10 & 0 & 30 & 0 & 60 & 0 & 90 \\
0.071 & 0 & 5 & 0 & 5 & 0 & 8 & 0 & 10 \\
\hline
\end{tabular}

b. Alberta's salt gradation

\begin{tabular}{|c|c|c|c|c|c|c|}
\hline \multirow{3}{*}{ Sieve size (mm) } & \multicolumn{6}{|c|}{ Mass percentage passing $(\%)$} \\
\hline & \multicolumn{2}{|c|}{ Alberta I } & \multicolumn{2}{|c|}{ Alberta II } & \multicolumn{2}{|c|}{ Alberta III } \\
\hline & $\min$ & $\max$ & $\min$ & $\max$ & $\min$ & $\max$ \\
\hline 10 & & & 100 & 100 & 100 & 100 \\
\hline 5 & 100 & 100 & 67 & 100 & 55 & 90 \\
\hline 2.5 & 98 & 100 & 40 & 85 & 5 & 60 \\
\hline 1.25 & 85 & 100 & 25 & 67 & 0 & 25 \\
\hline 0.63 & 35 & 100 & 15 & 45 & 0 & 8 \\
\hline 0.315 & 0 & 50 & 0 & 17 & --- & --- \\
\hline 0.16 & 0 & 8 & 0 & --- & --- & --- \\
\hline 0.089 & 0 & 3 & 0 & 3 & 0 & 3 \\
\hline
\end{tabular}

c. Ontario's salt gradation

\begin{tabular}{|c|c|c|c|c|}
\hline \multirow{3}{*}{ Sieve size (mm) } & \multicolumn{4}{|c|}{ Mass percentage passing $(\%)$} \\
\hline & \multicolumn{2}{|c|}{ Coarse } & \multicolumn{2}{|c|}{ Fine } \\
\hline & $\min$ & $\max$ & $\min$ & $\max$ \\
\hline 9.5 & 100 & 100 & & \\
\hline 4.75 & 30 & 100 & 100 & 100 \\
\hline 2.36 & 5 & 65 & --- & --- \\
\hline 1.18 & 0 & 30 & 35 & --- \\
\hline 0.6 & 0 & 10 & --- & --- \\
\hline
\end{tabular}

\section{d. Nova Scotia's salt gradation}

\begin{tabular}{ccc}
\hline \multirow{2}{*}{ Sieve size $(\mathbf{m m})$} & \multicolumn{3}{c}{ Mass percentage passing $(\%)$} \\
\cline { 2 - 3 } & Min & Max \\
\hline 14 & 100 & 100 \\
10 & 95 & 100 \\
5 & 20 & 90 \\
2.5 & 10 & 60 \\
0.63 & 0 & 10 \\
\hline
\end{tabular}


e. North Dakota DOT's salt gradation

\begin{tabular}{ccc}
\hline \multirow{2}{*}{ Sieve size $(\mathbf{m m})$} & \multicolumn{3}{c}{ Mass percentage passing $(\%)$} \\
\cline { 2 - 3 } & Min & Max \\
\hline 19 & 100 & 100 \\
12.5 & 100 & 100 \\
9.5 & 100 & 100 \\
4.75 & 95 & 100 \\
2.36 & 65 & 90 \\
0.6 & 5 & 25 \\
0.3 & 0 & 10 \\
\hline
\end{tabular}

f. Quebec's salt gradation

\begin{tabular}{ccc}
\hline \multirow{2}{*}{ Sieve size $(\mathbf{m m})$} & \multicolumn{2}{c}{ Mass percentage passing $(\%)$} \\
\cline { 2 - 3 } & Min & Max \\
\hline 12.5 & 100 & -- \\
10 & 95 & 100 \\
5 & 20 & 90 \\
2.5 & 10 & 60 \\
0.63 & --- & 11 \\
\hline
\end{tabular}

g. Manitoba's salt gradation

\begin{tabular}{ccc}
\hline \multirow{2}{*}{ Sieve size $(\mathbf{m m})$} & \multicolumn{2}{c}{ Mass percentage passing (\%) } \\
\cline { 2 - 3 } & Min & Max \\
\hline 9.5 & 95 & 100 \\
4.75 & 20 & 100 \\
2 & 10 & 85 \\
0.425 & 0 & 25 \\
\hline
\end{tabular}

h. New York State DOT's salt gradation

\begin{tabular}{|c|c|c|c|c|c|c|}
\hline \multirow{3}{*}{ Sieve size (mm) } & \multicolumn{6}{|c|}{ Mass percentage passing (\%) } \\
\hline & \multicolumn{2}{|c|}{ Type - A } & \multicolumn{2}{|c|}{ Type - B } & \multicolumn{2}{|c|}{ Type - C } \\
\hline & Min & $\operatorname{Max}$ & Min & Max & Min & Max \\
\hline 12.5 & 100 & 100 & 100 & 100 & 100 & 100 \\
\hline 9.5 & 100 & 100 & 100 & 100 & 100 & 100 \\
\hline 4.75 & 80 & 100 & 80 & 100 & 80 & 100 \\
\hline 0.3 & 0 & 18 & 0 & 25 & 0 & 35 \\
\hline 0.075 & 0 & 3 & 0 & 5 & 0 & 5 \\
\hline
\end{tabular}

i. Michigan DOT's salt gradation

\begin{tabular}{ccc}
\hline \multirow{2}{*}{ Sieve size $(\mathbf{m m})$} & \multicolumn{3}{c}{ Mass percentage passing $(\%)$} \\
\cline { 2 - 3 } & Min & Max \\
\hline 12.5 & 100 & 100 \\
9.5 & 95 & 100 \\
4.75 & --- & 90 \\
2.36 & -- & 60 \\
0.6 & --- & 15 \\
\hline
\end{tabular}


j. Washington State DOT salt gradation

\begin{tabular}{|c|c|c|c|c|c|}
\hline \multicolumn{3}{|c|}{ CATEGORY 4A } & \multicolumn{3}{|c|}{ CATEGORY 4B } \\
\hline \multirow{2}{*}{ Sieve size (mm) } & \multicolumn{2}{|c|}{ Mass percentage passing $(\%)$} & \multirow{2}{*}{ Sieve size (mm) } & \multicolumn{2}{|c|}{ Mass percentage passing $(\%)$} \\
\hline & $\min$ & $\max$ & & $\min$ & $\max$ \\
\hline 19 & 100 & 100 & 19 & 100 & 100 \\
\hline 4.75 & 20 & 100 & 6.3 & 75 & 85 \\
\hline 2.36 & 10 & 60 & 2.36 & 50 & 70 \\
\hline 0.6 & 0 & 15 & 0.6 & 10 & 20 \\
\hline
\end{tabular}
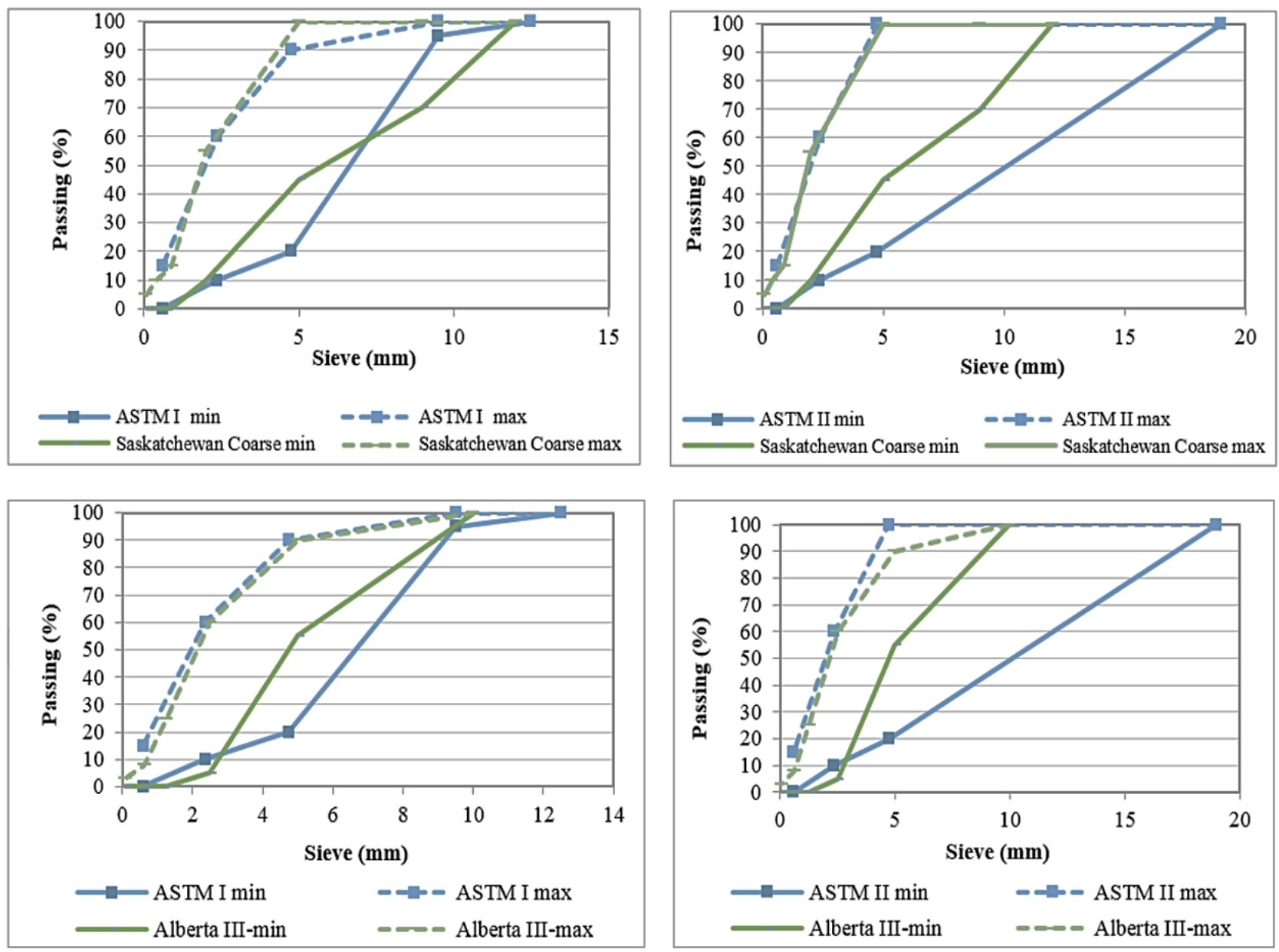

Figure 3. Comparison of ASTM I and II, Alberta and Saskatchewan coarse salt gradations

\subsection{Comparison of Canadian Jurisdictions' Coarse Salt Gradation to International Standards}

According to Table 8, the six coarse salt gradations that are used in Canadian provinces are Saskatchewan, Alberta, and Ontario's coarse salt gradation, and Nova Scotia, Quebec, and Manitoba's general salt gradation. According to Table 8, some of the provinces' coarse salt gradations, such as Saskatchewan, Alberta and Ontario, are compatible with more than one international standard. As presented in Figure 4a, among Canadian provinces with coarse salt gradation (6 provinces), $83 \%$ have gradation close to (or in range of) ASTM I, 67\% to ASTM II, and 50\% to BS III defined ranges for coarse salt gradation.

Table 8 shows four fine salt gradations used in surveyed Canadian provinces and US DOTs, which are Saskatchewan's medium and fine salt gradation, Alberta and Ontario's fine salt gradation, and North Dakota. According to Table 8, Saskatchewan's medium salt gradation, North Dakota's salt gradation, and Ontario's fine salt gradation are close to the Finnish standard, while Alberta's fine salt gradation is close to BS IV. As presented in Figure $4 \mathrm{~b}$, among the surveyed Canadian provinces and US DOTs with fine salt gradation (considering medium gradation for Saskatchewan as fine salt), $75 \%$ have gradation close to or in range of the Finnish standard and $25 \%$ to BS IV defined ranges for fine salt gradation. 
Table 8. Comparison of salt gradations with available standards

\begin{tabular}{|c|c|c|c|c|c|c|c|c|}
\hline Standard & ASTM I & ASTM II & $\begin{array}{c}\text { BS I } \\
\text { (Rock salt - } \\
\text { coarse) }\end{array}$ & $\begin{array}{c}\text { BS II } \\
\text { (Rock salt } \\
\text { - fine) }\end{array}$ & $\begin{array}{c}\text { BS III } \\
\text { (Vacuum \& marine } \\
\text { salt -coarse) }\end{array}$ & $\begin{array}{c}\text { BS IV } \\
\text { (Vacuum \& } \\
\text { marine salt - fine) }\end{array}$ & Swedish & Finnish \\
\hline Coarse & Almost I-R & $\mathrm{I}-\mathrm{R}^{*}$ & $\begin{array}{l}\text { Min: } C^{*} \\
\text { Max: } F^{*}\end{array}$ & $\begin{array}{c}\text { Min: C } \\
\text { Max: I-R }\end{array}$ & Almost I-R & $\mathrm{C}$ & $\mathrm{C}$ & $\mathrm{F}$ \\
\hline Mixed & $\begin{array}{c}\text { Min: I-R } \\
\text { Max: F }\end{array}$ & $\begin{array}{l}\text { Min: I-R } \\
\text { Max: F }\end{array}$ & $\begin{array}{c}\text { Min: I-R } \\
\text { Max: F }\end{array}$ & $\begin{array}{l}\text { Min: C } \\
\text { Max: F }\end{array}$ & Almost I-R & $\mathrm{C}$ & $\begin{array}{c}\text { Min: C } \\
\text { Max: I-R }\end{array}$ & $\begin{array}{c}\text { Min: C } \\
\text { Max: I-R }\end{array}$ \\
\hline Medium & $\mathrm{F}$ & $\mathrm{F}$ & $\mathrm{F}$ & $\begin{array}{c}\text { Min: I-R } \\
\text { Max: F }\end{array}$ & $\begin{array}{c}\text { Min: I-R } \\
\text { Max: F }\end{array}$ & $\begin{array}{c}\text { Min: C } \\
\text { Max: I-R }\end{array}$ & $\begin{array}{l}\text { Min: C } \\
\text { Max: F }\end{array}$ & $\begin{array}{c}\text { Min: I-R } \\
\text { Max: F }\end{array}$ \\
\hline Fine & $\mathrm{F}$ & $\mathrm{F}$ & $\mathrm{F}$ & $\mathrm{F}$ & $\begin{array}{c}\text { Min: I-R } \\
\text { Max: F }\end{array}$ & $\begin{array}{l}\text { Min: C } \\
\text { Max: F }\end{array}$ & $\begin{array}{c}\text { Min: I-R } \\
\text { Max: F }\end{array}$ & $\begin{array}{c}\text { Min: I-R } \\
\text { Max: F }\end{array}$ \\
\hline $\begin{array}{l}\text { Type III } \\
\text { (Coarse) }\end{array}$ & $\begin{array}{c}\text { Almost } \\
\text { I-R }\end{array}$ & $\begin{array}{c}\text { Almost } \\
\text { I-R }\end{array}$ & $\begin{array}{c}\text { Min: C } \\
\text { Max: I-R }\end{array}$ & $\begin{array}{c}\text { Min: C } \\
\text { Max: I-R }\end{array}$ & Almost I-R & $\mathrm{C}$ & $\mathrm{C}$ & $\mathrm{C}$ \\
\hline $\begin{array}{c}\text { Type II } \\
\text { (Medium) }\end{array}$ & $\mathrm{F}$ & $\mathrm{F}$ & $\begin{array}{l}\text { Min: I-R } \\
\text { Max: F }\end{array}$ & $\begin{array}{l}\text { Min: C } \\
\text { Max: F }\end{array}$ & $\begin{array}{l}\text { Min: I-R } \\
\text { Max: F }\end{array}$ & $\mathrm{C}$ & $\begin{array}{c}\text { Min: C } \\
\text { Max: I-R }\end{array}$ & $\begin{array}{c}\text { Min: C } \\
\text { Max: I-R }\end{array}$ \\
\hline Type I (Fine) & $\mathrm{F}$ & $\mathrm{F}$ & $\mathrm{F}$ & $\mathrm{F}$ & $\mathrm{F}$ & Almost I-R & $\mathrm{F}$ & $\mathrm{F}$ \\
\hline \multicolumn{9}{|c|}{ Ontario } \\
\hline Coarse & I-R & $\mathrm{I}-\mathrm{R}$ & Min: C & Min: C & Almost I-R & $\mathrm{C}$ & $\mathrm{C}$ & $\mathrm{C}$ \\
\hline Fine & Almost I-R & $\mathrm{I}-\mathrm{R}$ & $\mathrm{F}$ & $\mathrm{F}$ & $\mathrm{F}$ & $\mathrm{C}$ & $\mathrm{C}$ & I-R \\
\hline \multicolumn{9}{|c|}{ Nova Scotia } \\
\hline \multicolumn{9}{|c|}{ North Dakota (NDDOT) } \\
\hline & $\mathrm{F}$ & $\mathrm{F}$ & $\mathrm{F}$ & $\begin{array}{c}\text { Min: I-R } \\
\text { Max: F }\end{array}$ & Almost I-R & $\mathrm{C}$ & $\begin{array}{c}\text { Min: C } \\
\text { Max: I-R }\end{array}$ & I-R \\
\hline \multicolumn{9}{|c|}{ Quebec } \\
\hline & I-R & $\begin{array}{c}\text { Min: F } \\
\text { Max: I-R }\end{array}$ & $\begin{array}{c}\text { Min: C } \\
\text { Max: I-R }\end{array}$ & $\mathrm{C}$ & $\mathrm{C}$ & $\mathrm{C}$ & $\mathrm{C}$ & $\mathrm{C}$ \\
\hline \multicolumn{9}{|c|}{ Manitoba } \\
\hline & $\begin{array}{l}\text { Min: I-R } \\
\text { Max: F }\end{array}$ & $\begin{array}{l}\text { Min: I-R } \\
\text { Max: F }\end{array}$ & $\begin{array}{l}\text { Min: C } \\
\text { Max: F }\end{array}$ & $\begin{array}{l}\text { Min: C } \\
\text { Max: F }\end{array}$ & $\begin{array}{l}\text { Min: C } \\
\text { Max: F }\end{array}$ & $\mathrm{C}$ & $\mathrm{C}$ & $\begin{array}{c}\text { Min: C } \\
\text { Max: I-R }\end{array}$ \\
\hline \multicolumn{9}{|c|}{ New York State } \\
\hline Type A & $\begin{array}{c}\text { Min: F } \\
\text { Max: I-R }\end{array}$ & $\begin{array}{c}\text { Min: F } \\
\text { Max: I-R }\end{array}$ & $\mathrm{F}$ & $\begin{array}{c}\text { Min: I-R } \\
\text { Max: C }\end{array}$ & $\begin{array}{l}\text { Min: F } \\
\text { Max: C }\end{array}$ & $\mathrm{C}$ & $\mathrm{C}$ & $\mathrm{C}$ \\
\hline Type B & $\begin{array}{c}\text { Min: F } \\
\text { Max: I-R }\end{array}$ & $\begin{array}{c}\text { Min: F } \\
\text { Max: I-R }\end{array}$ & $\mathrm{F}$ & $\begin{array}{c}\text { Min: I-R } \\
\text { Max: C }\end{array}$ & $\begin{array}{l}\text { Min: F } \\
\text { Max: C }\end{array}$ & $\mathrm{C}$ & $\mathrm{C}$ & $\mathrm{C}$ \\
\hline Type C & $\mathrm{F}$ & $\begin{array}{c}\text { Min: F } \\
\text { Max: I-R }\end{array}$ & $\mathrm{F}$ & $\begin{array}{l}\text { Min: I-R } \\
\text { Max: C }\end{array}$ & $\begin{array}{l}\text { Min: F } \\
\text { Max: C }\end{array}$ & $\mathrm{C}$ & $\mathrm{C}$ & $\mathrm{C}$ \\
\hline \multicolumn{9}{|c|}{ Michigan DOT } \\
\hline & I-R & I-R & Almost I-R & $\mathrm{C}$ & $\mathrm{C}$ & $\mathrm{C}$ & $\mathrm{C}$ & $\mathrm{C}$ \\
\hline \multicolumn{9}{|c|}{ Washington State } \\
\hline Category 4A & $\begin{array}{l}\text { Min: C } \\
\text { Max: F }\end{array}$ & $\mathrm{I}-\mathrm{R}$ & $\begin{array}{c}\text { Min: C } \\
\text { Max: I-R }\end{array}$ & $\mathrm{C}$ & $\mathrm{C}$ & $\mathrm{C}$ & $\mathrm{C}$ & $\mathrm{C}$ \\
\hline Category 4B & $\begin{array}{l}\text { Min: F } \\
\text { Max: C }\end{array}$ & $\begin{array}{c}\text { Almost } \\
\text { I-R }\end{array}$ & $\begin{array}{l}\text { Min: F } \\
\text { Max: C }\end{array}$ & $\mathrm{C}$ & $\begin{array}{l}\text { Min: F } \\
\text { Max: C }\end{array}$ & $\mathrm{C}$ & $\mathrm{C}$ & $\mathrm{C}$ \\
\hline
\end{tabular}

* F: Finer, C: Coarser, I-R: In Range 


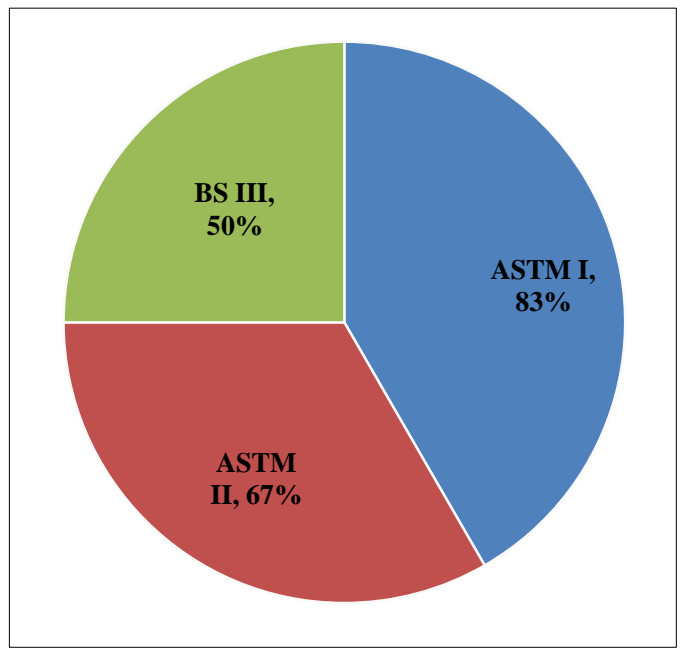

a) Coarse salt

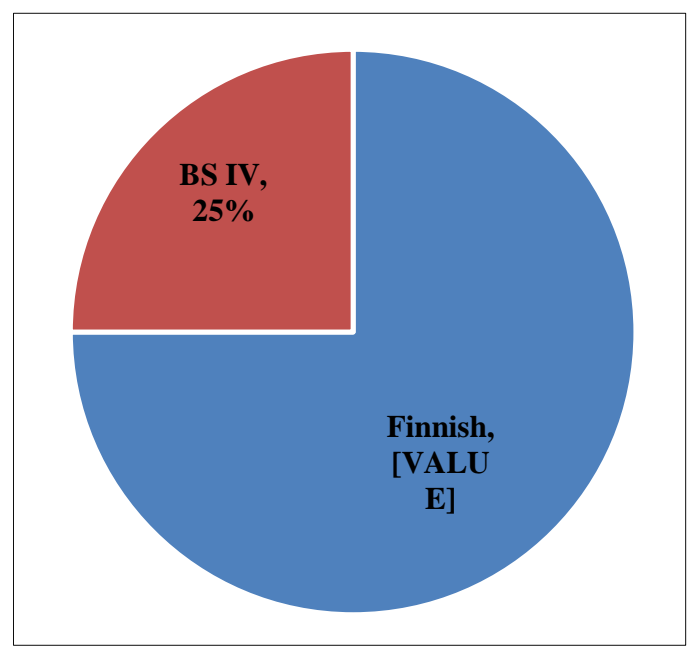

b) Fine salt

Figure 4. Similarity of surveyed Canadian provinces and US DOTs' coarse and fine salt gradation to international standards

\section{Conclusions}

Highway departments all over North America understand the importance of salt gradation in the ice control process. Most of the highways agencies have a pre-defined salt gradation specifications suited to their operations. The availability of these specifications facilitates the de-icing material procurement process as well as helping to maintain operating and safety standards. However, the salt gradation standards are not adhered to at all times by all organizations due to local situations. This research investigated various salt gradation standards for winter maintenance operations set by international standardization organizations such as ASTM and BS, and national standards in countries such as Finland and Sweden. Further, the research compared the salt gradation standards implemented by some Canadian provinces and US DOTs with international standards. The information regarding salt gradations in Canadian provinces and US DOTs was retrieved through a questionnaire survey. The following summarizes the survey results and the conclusions of the conducted comparative study:

- The literature review showed that in general, finer salt grades created higher wastage (anecdotal), and coarser grades were found to adhere to road surfaces better in direct applications

- The questionnaire survey results revealed that, although it is essential to conduct laboratory investigation and field trials to confirm the effectiveness of a specific salt gradation for winter road maintenance operations, none of the jurisdictions surveyed in this study conducted such investigations.

- Most of the jurisdictions responding to the research survey have well-defined salt gradation standards for winter maintenance, drawn from ASTM, BS, and other standards bodies. However, in practice the standards are not always followed depending on the availability of the correct supply;

- Jurisdictions with defined multiple standards for differing road conditions tend to adhere closely to their standards as they have been more rigorously defined;

- The results of the comparative study at different jurisdictions revealed that:

- Saskatchewan's medium and fine salts do not fit in ASTM and BS standard curves for salt standards. Its coarse salts are within ASTM II standards. However, ASTM II salts are primarily used in non-de-icing conditions, for aggregate stabilization, and other uses;

- Similar climatic jurisdictions such as Alberta, Ontario, Nova Scotia, and Quebec all use salts that fit readily into ASTM I specifications;

o North Dakota uses a very coarse salt that meets British Standards. This could be because of supply and/or windy road conditions in which coarse salt has better adhesion.

Given the scarcity of empirical tests as reflected through survey results, additional laboratory testing and largescale field trials are recommended to investigate the impact of slat gradation on the efficiency of winter road maintenance operations. Such laboratory tests and field trials would provide a better insight towards optimization of physical properties and application rates of various de-icing materials used in road winter maintenance operations under various environmental conditions. 
It is worth mentioning that the concluded results are limited to the received responses from the only six Canadian provinces and four US DOTs. The availability of additional information from other jurisdictions would enhance the reliability and representativeness of the results.

\section{Funding}

This research has been funded by the Saskatchewan Centre of Excellence for Transportation and Infrastructure.

\section{Acknowledgements}

The authors would like to thank all the respondents for participating in the survey and the Saskatchewan Centre of Excellence for Transportation and Infrastructure for sponsoring this research.

\section{Conflicts of Interest}

The authors declare no conflict of interest.

\section{References}

[1] Wu, Shujuan, Mulian Zheng, Wang Chen, Sitong Bi, Chongtao Wang, and Yifeng Li. "Salt-Dissolved Regularity of the SelfIce-Melting Pavement Under Rainfall." Construction and Building Materials 204 (April 2019): 371-383. doi:10.1016/j.conbuildmat.2019.01.129.

[2] Autelitano, Federico, Massimiliano Rinaldi, and Felice Giuliani. "Winter Highway Maintenance Strategies: Are All the Sodium Chloride Salts the Same?" Construction and Building Materials 226 (November 2019): 945-952. doi:10.1016/j.conbuildmat.2019.07.292.

[3] Fischel, M. "Evaluation of selected deicers based on a review of the literature," The Sea Crest Group, Colorado Department of Transportation, Denver, CO, Report No. CDOT-DTD-R-2001-15, 2001.

[4] L. Consultants and L. C. Limited, Guidelines for the selection of snow and ice control materials to mitigate environmental impacts vol. 577: Transportation Research Board, 2007.

[5] Shi, Xianming, David Veneziano, Ning Xie, and Jing Gong. "Use of Chloride-Based Ice Control Products for Sustainable Winter Maintenance: A Balanced Perspective." Cold Regions Science and Technology 86 (February 2013): 104-112. doi:10.1016/j.coldregions.2012.11.001.

[6] Nilssen, Kine, Alex Klein-Paste, and Johan Wåhlin. “Accuracy of Ice Melting Capacity Tests: Review of Melting Data for Sodium Chloride." Transportation Research Record: Journal of the Transportation Research Board 2551, no. 1 (January 2016): 1-9. doi:10.3141/2551-01.

[7] Muthumani, Anburaj, Laura Fay, Michelle Akin, Shaowei Wang, Jing Gong, and Xianming Shi. "Correlating Lab and Field Tests for Evaluation of Deicing and Anti-Icing Chemicals: A Review of Potential Approaches." Cold Regions Science and Technology 97 (January 2014): 21-32. doi:10.1016/j.coldregions.2013.10.001.

[8] S. Institute, "Snowfighter's Handbook," A Practical Guide for Snow and Ice Control Alexandria, VA, (2012).

[9] Kelting D. L., Laxon C. L., Review of effects and costs of road de-icing with recommendations for winter road management in the Adirondack Park: Adirondack Watershed Institute. (2010).

[10] Ketcham S., Minsk L. D., Blackburn R. R., and Fleege E. J. "Manual of practice for an effective anti-icing program: a guide for highway winter maintenance personnel." United States. Federal Highway Administration (1996).

[11] Dumont M. "Canadian Minerals Yearbook (CMY)-2008: Salt." 2009.

[12] Blackburn, R. R., McGrane E. J., Chappelow C. C., Harwood D. W., and Fleege E. J.. "Development of anti-icing technology: Strategic Highway Research Program." National Research Council Washington, DC, (1994).

[13] Blackburn, R. R. "Snow and ice control: Guidelines for materials and methods vol. 526." Transportation Research Board, (2004).

[14] Hossain, S. M. K. "Optimum De-icing and Anti-icing for Snow and Ice Control of Parking Lots and Sidewalks. Waterloo." $\mathrm{ON}$ : $\mathrm{PhD}$ thesis, University of Waterloo, (2014).

[15] Gerbino-Bevins, B. M. "Performance Rating of De-icing Chemicals." M.Sc. Thesis, Department of Civil Engineering, The University of Nebraska, Lincoln, Nebraska, (2011).

[16] ASTM. "Standard Specification for Sodium Chloride." in D 632, ed. USA: American Society for Testing and Materials (ASTM), 2012.

[17] B. S. (BS). "Specification for salt for spreading on highways for winter maintenance." in 3274, ed. UK: British Standard, (2011). 